\title{
Pattern of Malocclusion in Patients Undergoing Orthodontic Treatment at a Tertiary Care Teaching Hospital
}

\author{
Dr. Nidhi Giri, ${ }^{1}$ Dr. Anand Acharya, ${ }^{1}$ Dr. Rajkumar Jha ${ }^{2}$ \\ ${ }^{1}$ Department of Orthodontics, Nobel Medical College Teaching Hospital, Biratnagar, Morang, Nepal; \\ ${ }^{2}$ Department of Community Dentistry, Nobel Medical College Teaching Hospital, Biratnagar, Morang, Nepal.
}

\begin{abstract}
Introduction: Malocclusion can cause dental caries, periodontal disease and aesthetic problems. Malocclusion is the most common dentofacial abnormality found in human population. However, the awareness for orthodontic treatment is increasing

Objective: The aim of this research was to evaluate pattern of malocclusion in patients undergoing orthodontic treatment at Nobel Medical College Teaching Hospital of Biratnagar, Nepal.

Methods: Two hundred and eighty preoperative study casts (2018 Jun to 2020 Jun) of orthodontic patients aged from 12-55 years were selected from 680 patient's records of department of orthodontics of Nobel Medical College Teaching Hospital, Biratnagar. Standard protocol of Angle's classification of malocclusion was used to classify malocclusion and its traits were recorded. Data were entered in Microsoft Excel and descriptive statistics were calculated.
\end{abstract}

Results: The prevalence for malocclusion were 59.65\% (167) of Angle's class I, 35.71\% (100) of Angle's class II and 4.64\% (13) of Angle's class III malocclusion. Among various attributes of malocclusion, deep bite was the most common trait (188, 67.14\%). Increased overjet was found in 169 (60.35\%) subjects. Crowding and spacing were found in 164 (58.57\%), and 109 (38.92\%) respectively.

Conclusion: Angle's class I malocclusion is most prevalent malocclusion seen followed by Angle’s class II and Angle's class III.

Keywords: Angle’s classification; malocclusion; orthodontic treatment; pattern.

\section{INTRODUCTION}

Malocclusion, defined as an improper relationship between teeth in the opposite jaws, has been a prevalent disorder in recent decades. ${ }^{1}$ As stated by Angle "occlusion is the normal relation of the occlusal planes of the teeth when the jaws are closed" and malocclusion as per Dental Practice Board is justified as an abnormal occlusion, in which teeth are not in a normal position in relation to adjacent teeth in the same jaw and/or the opposing teeth when the jaws are closed. ${ }^{2}$

Prevalence of malocclusion varies in different parts of the world among different populations. Knowledge about the distribution of different malocclusions may help orthodontic practitioners in better understanding of the extent of malocclusion problem in a geographic location and help them in the proper orientation and management of treatment possibilities. ${ }^{3}$ There have been several studies investigating the prevalence of

Correspondence
Dr. Nidhi Giri
Email: nidhigiri65@yahoo.com
Citation

Giri N, Acharya A, Jha R. Pattern of Malocclusion in Patients Undergoing Orthodontic Treatment at a Tertiary Care Teaching Hospital. J Nepal Soc Perio Oral Implantol. 2021 Jan-Jun;5(9):26-8. various dentofacial characteristics, but only a few have been conducted on an orthodontic population..$^{4-7}$ Literature in this regard has been lacking in south eastern region of Nepal and hence the need of present investigation. Hence the aim of the present study was to examine the pattern of malocclusion in the patients visiting Orthodontic department of Nobel Medical College Teaching Hospital.

\section{METHODS}

A cross-sectional descriptive study was conducted in pretreatment dental casts of 280 patients visiting the Orthodontic department of Nobel Medical College Teaching Hospital, Biratnagar, Morang, Nepal. Data were collected retrospectively from the casts of June 2018 to June 2020 after obtaining ethical clearance from Institutional Review Committee of Nobel Medical College Teaching Hospital (Ref. 387/2020). The inclusion criteria were: i) Patients undergoing orthodontic treatment with veritable pretreatment records; ii) Individuals residing in province one region of Nepal; iii) Subjects with permanent dentition and fully erupted permanent first molar; and iv) Patients should be aged from 1255 years. The exclusion criteria were: i) No history of previous orthodontic treatment; ii) Patients with craniofacial anomalies; iii) Patients with syndromes, severe medical histories, and

This is an open access journal, and articles are distributed under the terms of the Creative Commons Attribution CC BY 4.0 Licence. 
developmental anomalies such as ectodermal dysplasia, cleft lip and palate, Down syndrome, extractions of any permanent teeth, prosthodontic treatment, or trauma to any tooth before the commencement of orthodontic treatment, hypodontia and hyperdontia.

Angle's classification of malocclusion was used to classify the dental malocclusion using the study models and patient's records by a single examiner. Several attributes of malocclusion included for the study of the nature of malocclusion were: over jet, spacing, crowding, deep bite, open bite which was measured clinically and in the study model. In addition, other problems like bimaxillary protrusion, retained deciduous teeth, cross bite, and scissor bite were also recorded. Informed consent was received prior to the clinical examination and for future use of the study cast. Data were entered to Microsoft Office Excel Sheet 2007 and analysis was done for descriptive statistics.

\section{RESULTS}

A total of 280 patients were included in the study and female (196, 70\%) patients were more compared to males (Table 1). The present study shows the distribution of malocclusion on the basis of Angle's classification which revealed 167 (59.65\%) of Angle's class I (Table 1). Among various attributes of malocclusion, deep bite was the most common trait with 188 (67.14\%). Increased over jet was found in 169 (60.35\%) subjects. Under space discrepancies, crowding, and spacing were found in 164 (58.57\%) and 109 (38.92\%) respectively (Table 2). Among the participants, most of them belonged to 18-40-year age group (Table 3).

Table 1: Distribution of sample according to gender, $\mathbf{n}$ (\%).

\begin{tabular}{|c|c|c|c|c|}
\hline Gender & Class I & Class II & Class III & Overall \\
\hline Male & $51(18.22)$ & $27(9.64)$ & $6(2.14)$ & $84(30)$ \\
\hline Female & $116(41.43)$ & $73(26.07)$ & $7(2.50)$ & $196(70)$ \\
\hline Total & $167(59.65)$ & $100(35.71)$ & $13(4.64)$ & $280(100)$ \\
\hline
\end{tabular}

Table 2: Distribution of different attributes of malocclusion according to gender.

\begin{tabular}{|c|c|c|c|c|c|}
\hline Traits & Sex & Class I & Class II & Class III & Total n (\%) \\
\hline \multirow{3}{*}{ Increased overjet } & Male & 30 & 24 & - & 54 \\
\hline & Female & 64 & 51 & - & 115 \\
\hline & Total & 94 & 75 & - & $169(60.35)$ \\
\hline \multirow{3}{*}{ Crowding } & Male & 28 & 14 & 4 & 46 \\
\hline & Female & 62 & 48 & 8 & 118 \\
\hline & Total & 90 & 62 & 12 & $164(58.57)$ \\
\hline \multirow{3}{*}{ Spacing } & Male & 24 & 10 & 3 & 37 \\
\hline & Female & 44 & 26 & 2 & 72 \\
\hline & Total & 68 & 36 & 5 & 109 (38.92) \\
\hline \multirow{3}{*}{ Deep bite } & Male & 40 & 17 & 2 & 59 \\
\hline & Female & 78 & 48 & 3 & 129 \\
\hline & Total & 118 & 65 & 5 & $188(67.14)$ \\
\hline
\end{tabular}

Table 3: Distribution of different attributes of malocclusion according to age.

\begin{tabular}{|c|c|c|c|c|c|}
\hline Traits & Age group & Class I & Class II & Class III & Total n (\%) \\
\hline \multirow{4}{*}{ Increased overjet } & 12-17 years & 24 & 34 & - & 58 \\
\hline & $18-40$ years & 74 & 42 & - & 116 \\
\hline & $>40$ years & 8 & 4 & - & 12 \\
\hline & Total & 106 & 80 & - & $186(66.42)$ \\
\hline \multirow{4}{*}{ Crowding } & $12-17$ years & 37 & 20 & 2 & 59 \\
\hline & $18-40$ years & 51 & 39 & 7 & 97 \\
\hline & 40 years & 3 & 2 & 2 & 7 \\
\hline & Total & 91 & 51 & 11 & $153(54.64)$ \\
\hline \multirow{4}{*}{ Spacing } & $12-17$ years & 12 & 13 & 2 & 27 \\
\hline & $18-40$ years & 57 & 19 & 3 & 79 \\
\hline & 40 years & 8 & 2 & 0 & 10 \\
\hline & Total & 77 & 34 & 5 & $116(41.42)$ \\
\hline \multirow{4}{*}{ Deep bite } & $12-17$ years & 40 & 35 & 1 & 76 \\
\hline & $18-40$ years & 61 & 50 & 3 & 114 \\
\hline & 40 years & 6 & 8 & 2 & 16 \\
\hline & Total & 107 & 93 & 6 & $206(73.57)$ \\
\hline
\end{tabular}




\section{DISCUSSION}

This study is on pattern of malocclusion in patients undergoing orthodontic treatment at Nobel Medical College Teaching Hospital of Biratnagar, Nepal. The present study showed that prevalent age group of orthodontic patients were mostly 18-30 years. This result is similar to the study done by Pandey et al. ${ }^{8}$ It was suggested the cause could vary from self-consciousness to social and matrimonial reasons. ${ }^{9}$

The results of the present study showed that females were more interested toward orthodontic treatment with the frequency of $70 \%$. This study is in accordance with the study done by Acharya et al. ${ }^{10}$ and also nearly similar to study done by Rahman et al. ${ }^{9}$ It was suggested the causes would be for marriage reason or self-consciousness.

The most frequent malocclusion was 59.65\% of Angle's class I followed by $35.71 \%$ of Angle's class II and $4.64 \%$ of Angle's class III malocclusion. This result is similar to study done by and Piya et al., ${ }^{11}$ Sharma et al., ${ }^{12}$ and Parajuli et al. ${ }^{13}$ This result is also in accordance with the study done by Acharya et al. where Angle's Class I malocclusion was found in 95 (63.33\%). ${ }^{9}$

Erum and Mubassar ${ }^{14}$ did a study in Pakistani population and found the prevalence of class II malocclusion (70.5\%) were higher followed by class I and Class III malocclusion respectively. This could be due to difference in sample size and racial predisposition to certain malocclusions.

In the present study the most frequently observed occlusal attributes in all type of malocclusion was deep bite (206, 73.57\%) followed by increased over jet, crowding, and spacing. This result is similar to the study done by Pandey et al. ${ }^{8}$ but in a study done by Sufia et al. ${ }^{15}$ crowding was seen most prevalent.

In this present study distribution of malocclusion and age was significant. This result is similar to study done by Pandey et al. $^{8}$

\section{CONCLUSION}

This study reveals that Angle's class I malocclusion was most prevalent with least common being Angle's class III malocclusion. Deep bite was the most common attributes. Treatment needs was high in 18-40 years of age group. By knowing the occlusal problems, their prevalence and need for appropriate treatment should be improved thus increasing the orthodontic scope in future.

\section{Conflict of Interest: None.}

\section{REFERENCES}

1. Proffit W, Field H, Sarver D. Contemporary orthodontics, 5th ed. St. Louis: Mosby; . Chapter 1:2-18.

2. Houston WJ, Stephens CD, Tulley WJ. A Textbook of Orthodontics, 2nd ed. Oxford: Wright; 1993.

3. Bishara S. Textbook of Orthodontics. 1st ed. Philadelphia: Saunders: 2001

4. Tang El, Wei SH. Recording and measuring malocclusion: A review of the literature. Am J Orthod Dentofacial Orthop. 1993 Apr;103(4):344-51.

5. Keski-Nisula K, Lehto R, Lusa V, Keski-Nisula L, Varrela J. Occurrence of malocclusion and need of orthodontic treatment in early mixed dentition. Am J Orthod Dentofacial Orthop. 2003 Dec;124(6):631-8.

6. Brunelle JA, Bhat M, Lipton JA. Prevalence and distribution of selected occlusal characteristic in the us population.,1988-91. J Dent Res. 1996 Feb 1;75(2):S706-13.

7. Foster TD, Day AJ. A survey of malocclusion and the need for orthodontic treatment in a shropshire school population. Br J Orthod. 1974 Apr;1(3):73-8.

8. Pandey BR, Singh S, Singh R, Mishra R, Mishra S, Ghart B. Pattern of malocclusion in patients seeking orthodontic treatment at medical colleges and teaching hospitals of chitwan, nepal. Orthod J Nepal. 2018;8(2):41-4.

9. Rahman MM, Jahan H, Hossain MZ. Pattern of malocclusion in patients seeking orthodontic treatment at dhaka dental college and hospital. Ban J Orthod Dentofac Orthop. 2013 Apr:3(2):9-11.

10. Acharya A, Bhattarai B, George D, Bhagat T. Pattern of malocclusion in orthodontic patients in south-eastern region of nepal. Orthod J Nepal. 2017;7(1):7-10.

11. Piya A, Shrestha BV, Acharya J, Khanal S, Bhattarai P. Pattern of distribution of malocclusion among patients seeking orthodontic treatment at dental college - Nepal medical college. J Nepal Dent Assoc. 2013;13(2):36-41.

12. Sharma JN. Pattern of distribution of malocclusions in patients seeking orthodontic treatment at bpkihs from sunsari district of nepal. Health Renaissance. 2010;8(2):93-6.

13. Parajuli U, Tuladhar SL, Bajracharya M, Pandey M. Prevalence of malocclusion and evaluation of orthodontic treatment need amongst patients in pokhara, nepal. Orthod J Nepal. 2018;8(1):7-10.

14. Erum G, Mubassar F. Pattern of malocclusion in orthodontic patients: A hospital-based study. J Ayub Med Coll Abbottabad. 2008 JanMar;20(1):43-7.

15. Rita SN, Hasan M, Dhar PP, Abrar MH, Sadat SM. Pattern of malocclusion in patients attended in orthodontic department of a tertiary level hospital. J Bangladesh Coll Phys Surg. 2019 Jul;37(3):119-23. 